\title{
Literature Appreciation and the Cultivation of Humanistic Quality of College Students with Hearing Impairment*
}

\author{
Qin Liu \\ College of the Special Education \\ Leshan Normal University \\ Leshan, China 614000
}

\begin{abstract}
Literature appreciation is a required course of liberal education for college students with hearing impairment. The interpretation and comprehension of this paper is closely associated with the world outlook, outlook on life and values of college students with hearing impairment and involves the improvement of humanistic quality. The ability of students in language perception can be cultivated through reasonably setting goals, deliberately choosing the course content of literature appreciation and creating context and strengthening reading. At the meantime, we can introduce media to arouse their interest and make flexible use of the model of "bilingual teaching", organize student activities and continuously innovate in teaching methods, in order to meet the special needs of students with hearing impairment in learning and give full play to the role of literature appreciation in the cultivation of humanistic quality.
\end{abstract}

Keywords-literature appreciation; college students with hearing impairment; humanistic quality

\section{INTRODUCTION}

In recent years, China and Chinese Communist Party have paid an increasing number of attentions to the special education. The higher education for the disabled has also shown a good development trend. A lot of special education colleges (departments) have provided courses of literature appreciation and art appreciation to strengthen the training of application-oriented talents in the special education of universities and enhance the humanistic quality of college students with hearing impairment. For example, the contents of the introduction to literary works, text interpretation, the appreciation of Chinese and foreign literature, the appreciation and analysis of films and televisions and drama appreciation involved in the course of College Chinese have been provided to improve the appreciation level of college students with hearing impairment for various literary works and reach the goal of training the comprehensive quality and humanistic quality of college students with hearing impairment. The author has taught the course of literature appreciation for

*Fund program: Year 2016 research program of the Research Center for the Ideological and Moral Education of Adolescents of Sichuan, the Society for Research on Adolescence of Sichuan, "Current Situation and Countermeasures for the Ideological and Moral Education for Adolescents with Hearing Impairment in Sichuan Province" (SCQSN2016YB12). college students with hearing impairment in the major of art design and the special education major (undergraduate). In teaching I have found the overall ability of literature appreciation of the college students with hearing impairment in the four classes is relatively low. They often only pay attention to the superficial when appreciating literary works. It is difficult for them to deeply analyze the beauty of literature and the artistic appeal of works. What is the relevance between literature appreciation and humanistic quality? How to cultivate the humanistic quality of college students with hearing impairment by virtue of literature appreciation? This paper will explore to attract the common attention of colleagues in the special education circle and make concerted efforts to lift the humanistic quality of college students with hearing impairment.

\section{LITERATURE APPRECIATION AND HUMANISTIC QUALITY}

\section{A. Literature and Literature Appreciation}

What is literature? Aristotle says, "Literature is the imitation of nature"; Plato says, "Literature is the imitation of the idea world"; other people say, literature is the "mirror" of society and the reflection of life; literature is the interaction of the era and the record of history; literature is the development history of human soul. Literature is the intellectual product that takes language as the tool, artistically reflects human life and conveys human emotion [1]. Literature appreciation is an aesthetic and mental activity of readers in reading literary works. In the aesthetic and mental activity, readers acquire the concrete feeling and experience of artistic image shaped by literary works through the media of language. It strikes a chord ideologically and emotionally and makes readers enjoy beauty, experience beauty, comprehend beauty and acquire beauty and obtain enormous pleasure spiritually. As a special cognitive activity, literature appreciation is different from the reading of scientific works and is an activity of thinking that focuses on perceptual understanding.

\section{B. The Main Connotation of Humanistic Quality}

The word "humanity" is first seen on the Book of Changes in China, "Men and women exist naturally. Men represent 
hardness and women softness. The intersection of hardness and softness is nature; men and women marry and form families and a country and then human relations emerge, this is edification in rites and music. The ruler must observe the operation law of nature to elaborate the lifecycle closely related to human activities and grasp the ethical order to educate the subjects"[2]. According to the historical background at that time, the "humanity" here can be interpreted as the edification in rites and music. Nowadays, the frequently-mentioned "humanity" in general refers to the cultural phenomena in human society and the core content of human civilization. Attainment is the condition required by individuals to realize reasonable and effective communication and interaction with the outside world. Attainment means knowledge is internalized into people's life and behaviors [3]. What is humanistic quality? Humanistic quality refers to people's internal cultivation related to humanistic spirit, their spiritual qualities and basic conservation and includes the behaviors externalized by internal quality and spirit [4]. In recent years, humanistic quality has become a crucial index to assess the comprehensive quality of a person.

\section{THE ROLE OF LITERATURE APPRECIATION IN THE Cultivation of THE Humanistic Quality of COLLEGE STUDENTS WITH HEARING IMPAIRMENT}

\section{A. To Establish the Correct "Three Values" and Promote the Formation of a Healthy Personality}

The college period is a key period that a person's ideology gradually matures. In this period, the world outlook, outlook on life and values (hereinafter referred to as "three values") gradually form and finalize. General Secretary Xi Jinping addresses, "we must establish the correct world outlook, outlook on life and values. After grasping the passkey, we will naturally and clearly see the right and wrong, the primary and the secondary, true and false, the good and the evil, beauty and ugliness in society and life course. And we will naturally make the correct judgments and selection" [5]. The world outlook will influence people in understanding the world around us. The outlook on life determines how to choose our life path. The values determine how to judge the rights and wrongs, the good and the evil, beauty and ugliness. Most college students with hearing impairment spend in a relatively closed boarding management mode in schools for the deaf from primary school to senior high school. After entering colleges, the relatively open, free and rich college life will probably make them have the thoughts and behaviors that blindly pursue individuality and accept free choice. Therefore, it is essential to pay attention to the education of "three values" for college students with hearing impairment. In the process of literature appreciation, the ability to interpret and appreciate text has a close relationship with the world outlook, outlook on life and values of each student, and has indirectly reflected the opinions and attitudes of students toward right and wrong, the good and the evil, beauty and ugliness in the objective world. Literary works are used to guide students to recognize the society and learn to deal with the relationship with others and themselves. Especially for those college students who have hearing impairment, unstable emotions and easily become depressed when encountering obstacles, reading literary works with positive spirit will help them correctly recognize themselves and obtain the force of growth spiritually and promote the formation of their healthy personality. For example, Su Shi, the great ideologist and litterateur, had met with setbacks in his life, and his official career was also ups and downs for several times. However, he still held a positive attitude towards the setbacks in his life and had done tremendous events that benefit the nation and the people. In the appreciation of the literary works of authors like Su Shi, it is a very effective way to make college students with hearing impairment absorb the force of forwarding and build a healthy and positive psychological state.

\section{B. To Comprehend the Beauty of Humanity and the Glamour of Classics and Cultivate Humanistic Feelings}

The excellent literary works especially the classic and famous literary works are the precious artistic essence of human that lives through time and tide and exists after screening and contain the profound and extensive Chinese culture and humanistic spirit. In the appreciation of these works, teachers must guide college students with hearing impairment to read and comprehend with an attitude related to literature, fully excavate the humanistic connotation of works and appreciate the society, humanity, emotion and culture in it. For example, in the appreciation of poems, students can be led to read and appreciate the soul-touching beauty of poetries, feeling the majestic momentum of "Flying waters descending straight three thousand feet, till I think the Milky Way has tumbled from the ninth height of Heaven", appreciating the indignant and compassionate feelings of "In the mansions, rolling luxury allows wine and meat to go rotten away; On the streets, grinding poverty causes dead bodies to freeze and decay", stimulating the positive spirit of "In order to take in a boundless view, Ascend another floor" and appreciating the romantic charm of "I would like compare the West Lake to a beauty who looks perfect in both heavy and light make-up". All in all, literature appreciation will successfully enrich the internal spiritual conservation and emotional world of college students with hearing impairment and widen their visions and feelings of understanding the outside world.

\section{To Cultivate Taste and Enhance Aesthetic Judgment}

Anatole France, a renowned French writer once compared literature appreciation to "the ramble of soul among masterworks", which had shown the role of literature appreciation in shaping the soul and cultivating taste. Literature appreciation will guide college students with hearing impairment to gradually enrich knowledge and know great foreign ideologists from literary works, from Homer to Diderot, from Balzac to Tagore, from Pushkin to Einstein, and understand foreign culture and exoticism; it also makes them absorb the power of personality, worshiping the righteous and high-minded characters of $\mathrm{Qu}$ Yuan, Tao Yuanming and $\mathrm{Su}$ Shi, receiving the heart of benevolence in "Do not do to others what you do not want done to yourself" advocated in The Analects of Confucius, remembering the life directions of $\mathrm{Lu}$ Yao and Helen Keller and bravely facing the bad fortunes and good fortunes in life. The appreciation of classic literature and the deep learning of languages make college students with hearing impairment immerse in the spiritual world reflected by 
works to obtain inspiration and experience, bring them more thinking on culture, literature and life, then lift their literature level, cultural connotation and aesthetic ability and promote the comprehensive improvement in humanistic quality of college students with hearing impairment.

\section{WAYS TO CULTIVATE THE HuMANISTIC QUALITY OF} COLLEGE STUDENTS WITH HEARING IMPAIRMENT BY VIRTUE OF LITERATURE APPRECIATION

\section{A. To Reasonably Set Objectives and Elaborately Choose Course Content}

Because of the physiological defect, the learning contents and requirements of students with hearing impairment in the educational phases from primary school to senior high school are lower than that of students with a normal hearing. Compared with healthy students, those with hearing impairment are relatively weaker in understanding and applying languages and words. After entering colleges, in face of literature appreciation, a required course of liberal education not included in Chinese major, college students have difficulties in simultaneously learning and understanding the deep knowledge and connotation contained in the course together with college students with a normal hearing. Therefore, it is necessary to reasonably set course objectives according to the real learning ability of college students with hearing impairment. The major course objective of literature appreciation for college students with hearing impairment is to cultivate the humanistic quality of students. The requirement of applying literature knowledge and language cannot be too high. In terms of setting the course content, since there are no textbooks especially for the literature appreciation of college students with hearing impairment, we can refer to College Chinese. After taking advice from college students with hearing impairment, we have chosen some chapters, including excellent poetries, essays, novels, dramas, and films, literature of science fiction and network literature at all times and in all over the world. Other contents can be supplemented properly.

\section{B. To Cultivate the Ability of Language Perception by Way of Literature Appreciation}

The literature appreciation of college students with hearing impairment mainly involves reading classics to improve their analytical ability and aesthetic ability. How to guide college students with hearing impairment to appreciate the beauty of literature classics and understand the deep connotation of literary works? I think in the process of literature appreciation, we must pay attention to cultivating the language sense of college students with hearing impairment, encouraging them to perceive and understand language when reading and communicating with people, in order to gradually strengthen the aesthetic ability and improve their humanistic quality.

1) To create language environment and understand the connotation of sentence: The training of language sense requires a relatively good reading and thinking ability of college students with hearing impairment. In the process of literature appreciation, we can make use of the junction of daily reading and communication to make students more sensitive to characters. Teachers should actively create the language environment that makes college students with hearing impairment exert their ability in spoken language and gesture language. In regard to some articles, we can let students share and exchange after reading the text and express the text contents via role play and text-based drama. For example, in Oh, Mother, My Insane Mother written by Wang Hengji, the fragment that the mother who has left home for five years now comes back home is as follows:

Several litter friends run at full speed to tell me, "Little Shu, go and see, your mother has come back, you insane mother has come back." I am overjoyed and go out immediately... My mother eventually stares at me fixedly and says to me with a grinning, "Little Shu...ball...ball!" She stands up and swings the balloon gripped in her hand ceaselessly and puts it in my arms forcedly and fawningly... I turn back and run away at once.

College students with hearing impairment can conduct role play for the above content, create situation and then read the text then discuss and communicate to understand the deep love of the "insane mother" who has left home for five years. Situational teaching can be created in other similar texts to guide students to experience the connotation of sentences.

2) To strengthen reading and appreciate the value of works: Wide reading is required to develop a good language sense. Teachers should encourage college students with hearing impairment to read more literary works, "To Read More Books, Read Good Books". Students must read and appreciate the values in both textbooks and books for outside reading to accumulate knowledge of literature and enrich personal knowledge. At the same time, teachers should guide college students with hearing impairment to "experience in the book" and "be an onlooker to read the book". When appreciating works, we should resonate with the author spiritually and conduct a "soul-to-soul" literary experience with the author. For example, after the appreciation of Lin Daiyu's Elegy on Flowers in A Dream in Red Mansions, teachers can guide students to jointly appreciate the ideological value of this poem. The poem is not blindly grieved but still has a suppressed and indignant sense. "I wish to have two wings under my arms to fly, after you unto the farthest end of the sky. At the farthest end of the sky, where can I find the grave of your fragrance lie? It is better in silk to shroud your petals fair, with a handful of clean earth as your attire. For pure you have come and pure you repair, lest you fall into some foul ditch or mire." The verses have shown the aloof and proud and stalwart character of being unwilling to be humiliated and yield when Lin Daiyu expects freedom and happiness that are beyond the reach of her. This is the ideological value of the work. Another value of this poem is that it has provided us with an important clue for the love tragedy between Jia Baoyu and Lin Daiyu written by Cao Xueqin. In a word, except for understanding and perception, in the reading of articles, students should be guided to appreciate the ideological value 
and artistic characteristics of works from the perspective of literature and art.

\section{To Innovate in the Teaching Method and Adapt to the Special Needs of Students}

College students with hearing impairment favor learning in a free and relaxed state. Their cognitive features and learning needs must be taken into consideration in the selection of teaching method. Under the mode of "bilingual teaching", teachers should give full play to their subjectivity and train their interest in literature appreciation.

1) To introduce network media and arouse interest: Most middle and primary schools for the deaf adopt the closed-off management. Students in these schools have a narrow scope of knowledge and little contact with the society. It has impeded their deep analysis and understanding of knowledge about Chinese. After entering colleges, students with hearing impairment share the same resources with students with normal hearing. In the process of literature appreciation, teachers guide college students with hearing impairment to effectively make use of network resources such as image and text in WeChat, online excellent courses and movie and television play. The visualized resources are combined with literary works through network media. For example, after seeing the film of Jane Eyre, because of the entertainment feature of films and television, students with hearing impairment have the interest of reading the novel of Jane Eyre written by Charlotte Bronte anew, then deeply analyze and comprehend as well as proactively ponder the values and connotation of the literary work. In addition, college students with hearing impairment who are the generation after the 1990s would like to accept new things. Teachers can add some stories about literati and the background stories of works. The teaching contents should be attractive and interesting for college students with hearing impairment, making them feel the ideological connotation conveyed by literary classics. Meanwhile, it should make them feel the literary works span time and space and infinitely readable.

2) To make flexible use of the model of "bilingual teaching": To respect and comply with the features and needs of college students with hearing impairment in language learning, the model of "bilingual teaching" should be flexible adopted in teaching to make them learn Chinese and English then grasp knowledge through gesture language and spoken language. In the class of literature appreciation, teachers can communicate with college students who have residual hearing through spoken language; when communicate with students who have lost hearing, teachers should use gesture language and spoken language at the same time, flexibly translate text content and realize barrier-free communication with students, in order to make them grasp the corresponding teaching content. When playing European and American movie and television play, teachers can translate English into Chinese to help students understand the contents. In short, it is necessary to flexibly adopt language for communication to improve the effectiveness of teaching, according to the special learning needs of college students with hearing impairment.

3) To take part in activities and give play to the subjectivity of students: Confucius says, "Those who love it are better than those who know it, and they who delight in it are better than those who love it". The sentence has indicated "those who love it" is the highest level of learning activities. Only with a highly pleasant mood can students learn effectively. Like those with normal hearing, college students with hearing impairment hate dull and rigid teaching. Therefore, in terms of teaching form, teachers can encourage students to proactively take part in activities of literature appreciation and innovate in the classics. For example, literary works can be adapted into text-based drama, drama and micro films. Students can be encouraged to excavate the connotation of literary works and improve humanistic quality in the abundant and colorful activities related to literature appreciation. Except for part of the explanation of teachers, students should be required to focus on independent study after class. Reading party, introduction class, competition of sign language in story telling and essay competition can be organized to arouse the passion of college students with hearing impairment in reading literary classics. What's more, the books that are popular among students can be centered to organize activities of literature salon and open lectures on literature, which gather college students with hearing impairment and the same interest together. Teachers and students discuss and communicate freely and express their experience of reading, hearing the inspiration and thinking of others, in order to promote the communication and interaction among students and give full play to their enthusiasm in learning.

\section{CONCLUSION}

College students are the group that requires special attention. The teaching of literature appreciation course is worthy to be further discussed. Our training objective is to guide college students with hearing impairment to appreciate literary works at the same time further consolidate what they have learnt. Besides, we aim at enriching their humanistic knowledge and ideological connotation, training their aesthetic ability and creativity and improve their comprehensive quality in order to lay a solid foundation for them to smoothly step into society and live happily in the future.

\section{REFERENCES}

[1] Liu Xiaobing. The Course of Literature Appreciation and the Cultivation of Humanistic Feelings of College Students [J], Theory Research, 2010 (16): 231. (in Chinese)

[2] Huang Shouqi, Zhang Shanwen. Translation and Annotation of the Book of Changes [M], Shanghai: Shanghai Classics Publishing House, 2007: 132. (in Chinese)

[3] Wang Shijing, Gu Su. Thinking and Exploration on the Cultivation of Humanistic Quality of College Students - Enlightenment on the Holistic Education of Hong Kong University of Science and Technology [J], Hubei Social Sciences, 2015 (6): 179. (in Chinese) 
[4] Liu Ningning, Duan Xuming. Analysis on the Current Situation and Influence Factor of the Humanistic Quality of Contemporary College Students [J], the Guide of Science and Education, 2018 (19): 1. (in Chinese)

[5] Xi Jinping. The Young Must Consciously Practice Socialist Core Values - Speech on the Symposium with Teachers and Students from Peking University [N], People's Daily, May 5 ${ }^{\text {th }}, 2014$ (2). (in Chinese) 